\title{
Psychological Sense of Community Responsibility and Diversity in Old Age: A Qualitative Study of Urban Older Adults in India
}

\author{
Nina Kavita Heggen Bahl*, Ingunn Hagen \\ Department of Psychology, Norwegian University of Science and Technology, Trondheim, Norway \\ Email: *Nina.Bahl@ntnu.no
}

How to cite this paper: Bahl, N.K.H. and Hagen, I. (2017) Psychological Sense of Community Responsibility and Diversity in Old Age: A Qualitative Study of Urban Older Adults in India. Open Journal of Social Sciences, 5, 387-401.

https://doi.org/10.4236/jss.2017.57024

Received: May 22, 2017

Accepted: July 23, 2017

Published: July 26, 2017

Copyright (c) 2017 by authors and Scientific Research Publishing Inc. This work is licensed under the Creative Commons Attribution International License (CC BY 4.0). http://creativecommons.org/licenses/by/4.0/

\begin{abstract}
The aim of the present study is to explore older adult people's meaning of psychological sense of community (PSOC), a key element in individual and community well-being. Using thematic and discourse analytical approaches we have in an in-depth and context-sensitive way analyzed interview material from twelve urban older informants residing in the heterogenic mega-city of Mumbai. Several themes included in the samples meaning of PSOC confirm established dimensions of the concept. However, key aspects of their meaning system more closely relate to the concepts PSOC-R and diversity and demonstrate these inherent concepts as highly culturally bound and context-sensitive at a city and national level.
\end{abstract}

\section{Keywords}

Psychological Sense of Community, Older Adults, Meaning, Diversity, Mumbai, India

\section{Introduction}

With today's aging world population a global concern is how to promote the well-being of older adult populations. To feel devoted to and included in one's communities are important aspects of individual as well as community well-being [1]-[6]. One of the ways that community psychology is pursuing individual and community well-being is through its core value "psychological sense of community" (PSOC) [7]-[12]. Several studies from non-Western contexts have demonstrated the four dimensions in McMillan and Chavis' (1986) operationalization as central to peoples meanings (e.g. Brodsky [13]): a) membership, or the experience of belonging and identification with those who are accepted as part of the community; b) mutual influence, or the acknowledge- 
ment of community influence and, simultaneously an awareness of having influence on one's community; c) integration and fulfilment of needs, or the expectation and reinforcement of having ones needs met through the community and; d) shared emotional connection, or the experience of having a shared community experience and history with other members. There are, however, few studies of later-life PSOC [14], especially in non-Western societies, where the majority of the older population will reside in the future. Fast changing structures and meaning systems are taking place in the urban context of India, which have the second largest older adult population in the world [15]. Insight into what PSOC is for older adult individuals' residing in urban India is a central part of preparing for their future individual and community well-being.

This study aims to explore urban Indian older adults' meaning of PSOC. It provides three novel contributions to the field: First, to our knowledge, it is the first study of PSOC in India. Secondly, as few have done before, we study PSOC among older adults. Finally, of vital importance to the established understanding of PSOC as a context sensitive and culturally-bound concept [6] [11] [13] [16] [17] [18] [19] [20] and that cultural context affects our meanings and experiences of aging [21], we study later-life PSOC within the interaction of individual and cultural meaning systems.

\section{The Indian Context and Older Adults}

India's cultures have traditionally been characterized by vertical collectivistic values; A shared conviction of the self as interdependent with some in-group (e.g. the family), a social pattern consisting of closely linked individuals [22] [23] as well as the appreciation for hierarchy, as important parts of the culture [23] [24] [25]. Today, collectivistic meaning systems co-exist with individualistic ones, mainly in urban areas [26]. Additional core values include spirituality [27], meeting social obligations [28], and family-oriented values [29] [30]. Furthermore, Hindu understandings of the different stages across the lifespan ${ }^{1}$ [31] [32] [33] and the caste system [34] [35] prescribe what old age should be. Traditionally older people in India have been taken care of by the extended family and possessed the role of an authority and a source of wisdom within the family. Today, however, the nuclear family structure is becoming the norm, particularly in urban areas [36]. Social networks and communities outside the family may thus become more important for the urban older adult in order to maintain their PSOC.

We are studying the concepts of older adult people living in Mumbai, the largest urban population in India. The megacity holds a population of over 21 million people [37] and the largest slum in Asia [38]. Due to rapid migration (the majority of the older populations in urban areas in India are migrants from other states in India [15] [30]) the city's culture is characterized by a fusion of

${ }^{1}$ In the Hindu scripture called "Bhagvad Gita" Human life is divided into four stages (ashramas): The first two stages of life (Bramacharya and Grishashtha) are devoted to learning trade and performing duties, the latter two stages (Vanaprasthaand Sanyasa) are for everyone to withdraw from day-to-day material activities and social bonds to eventually lead a spiritual life (see Gokhale, 2003, Bhawuk, 2008). 
Indian cultures.

\section{Method}

\subsection{Informants}

Twelve older adult informants participated in the study. This is a very small sample in respect of the older adult population in Mumbai. However, given the importance of cultural context for understanding conceptualizations of PSOC [20] [39], a in-depth and context-sensitive analysis was prioritized over sample size.

To recruit older adult informants, scientific staff at the Tata Institute of Social Science (TISS) invited older adults by phone. The following admission criteria were used; above 60 years of age, speak English and living in Mumbai. A combination of purposive and convenience sampling was used in the study. Ensuring a sample that could inform us about PSOC in old age from different perspectives, we included members of the Lions Club in Mumbai (three men, two women) and older adults who were not active in social or political groups (three women). Finally, older adults living in institutions (three men; two of them active as volunteers, one woman) were included. Two day-care centres were chosen as an institutional setting suitable for recruiting older adults sufficiently healthy to participate in the study. All the informants were acquaintances of one of the involved staff members from TISS. Furthermore, the following demographic variables characterized the sample (Table 1). All informants reported to be Hindu.

\subsection{Interviews}

Qualitative interviews have been a useful method for getting information about

Table 1. Demographical characteristics of the sample.

\begin{tabular}{ccccccc}
\hline Informant $^{1}$ & $\begin{array}{c}\text { Marital } \\
\text { status }\end{array}$ & $\begin{array}{c}\text { Highest level } \\
\text { of education }\end{array}$ & $\begin{array}{c}\text { Residential } \\
\text { area of } \\
\text { Mumbai }\end{array}$ & $\begin{array}{c}\text { Years of } \\
\text { residency }\end{array}$ & $\begin{array}{c}\text { Number of } \\
\text { children }\end{array}$ & $\begin{array}{c}\text { Number of } \\
\text { family members } \\
\text { in the home }\end{array}$ \\
\hline F77 & Widow & MA & Suburban & 3 & 2 & 3 \\
F74 & Widow & BA & Suburban & 15 & 1 & 4 \\
F61 & Married & BA & Suburban & 10 & 3 & 1 \\
F82 & Married & PhD & Suburban & 52 & 2 & 1 \\
F67 & Married & BA & Suburban & 4 & 2 & 1 \\
F80 & Widow & Basic school & Urban & 6 & 2 & 0 \\
M81 & Widower & BA & Urban & 4 & 2 & 0 \\
M67 & Married & BA & Suburban & 37 & 1 & 1 \\
M65 & Married & BA & Suburban & 39 & 1 & 2 \\
M60 & Married & MA & Suburban & 20 & 2 & 4 \\
M70 & Widower & High school & Urban & 1 & 0 & 0 \\
M69 & Widower & MA & Suburban & 32 & 2 & 0 \\
\hline
\end{tabular}

${ }^{1}$ Informants are represented with codes indicating gender (F, female and M, male) and the informant's age. 
PSOC in non-Western cultural contexts [13]. Aiming for data that provided a detailed understanding of the samples meaning of PSOC we chose semi-structured interviews, making sure that the informants had a chance to express their understanding and at the same time have some overall structure to the conversation [40]. The interview guide consisted of two sections; part one contained questions about demographical variables (age, gender, marital status, highest level of education, residential area of Mumbai, years of residence, number of children, and number of family members residing in their home). Part two included open-ended questions about the meaning of community and PSOC (e.g. "What comes to your mind when you think of the word 'community'?", "What meaning do you relate to the concept 'sense of community'?" and "In which way would you say a sense of community is important to you as an elderly person?").

The interviews were performed in English. Two research assistants were present during the interviews to make sure language did not become a challenge. The interviews were recorded using a digital voice recorder and ranged from 13 minutes to 1 hour and 36 minutes. The study was approved by national ethical guidelines (Norwegian Centre for Research Data) and TISS.

\subsection{Analyses}

Thematic Analysis. In psychology thematic approaches are a common way of analyzing data from interviews. Braun and Clarke (2006) provide an accessible, systematic and rigorous approach to identify and analyze frequent and central themes as part of peoples meanings [41] [42] [43]. This was essential for the aim of the study, and the approach was used as the initial analysis of the data set, consisting of verbatim transcriptions of the second section of the interviews. As will be further discussed, we decided to combine the thematic analysis with discourse analysis in order to explore the samples meanings of PSOC in depth and in a context-sensitive way.

The first four steps of the thematic analysis were performed to capture the most frequently mentioned and common themes. First, the researcher (corresponding author) read through the transcripts to become familiar with the material and generate initial codes. To make sure codes were not missed out in the first read through, the researcher went back to the data set to search for additional codes. To develop themes the most central characteristics were noted for each candidate theme and sub-theme. Then, the researcher reviewed themes by going through the data-set to see if and how each theme interacted with other themes and demographical variables. Finally, the review was extended by highlighting themes in the data set with different colors, checking if the parts that were not colored provided further insight to the samples meanings of PSOC. In this process ten themes were identified. They were: "Helping and caring for others", "Adaptation and acceptance", "Reciprocity", "Safety and welfare structures", "Shared elements", "Sense of belonging and attachment", "Community satisfaction", "Respect", "Residential investment and action" and "Heterogeneity". 
Discourse Analysis. An a priori assumption in discourse analysis is that meanings of concepts change with time. This process happens through discourse, the interaction between spoken language (the way individuals and groups speak about something), and culture as part of meaning systems prescribing and describing the common sense of society [44] [45] [46] [47]. Discourse analysis provides several approaches and tools [45] [48]. Gee [49] offers an approach to analyze meaning systems in a data set and is considered appropriate for our study. He argues that what is taken for granted or common sense is most essential for understanding meaning. As one the tools within his approach 'The making strange tool' focuses on the taken for granted elements in the data set. The researcher enquires into what the informants implicitly take as natural and true. Applying the tool it became obvious that some words used by the participants reoccurred in the data set. These words were used to search by in the data set, as a way of concretizing the use of the tool. Eight words were typically used when talking about taken for granted notions: "Should/Shouldn't", "Must", "Have to", "Absolutely", "Normal/Normally", "Isn't/That is not", "Right" and finally "Of course". Searches were made for these words and sections from the data set including the words were extracted and put into a separate document to analyze these with the discourse analysis tool. Four recurring taken for granted aspects of PSOC were identified: "Community development", "Owing the community", "Community membership", and "Social influence". Using the tool to review the themes gave an in-depth understanding of what was taken for granted, and provided the possibility of revealing additional themes. The findings from this analysis were evaluated and then merged with the findings from the thematic analysis, making sure that the most central and common themes as well as the taken for granted dimensions of PSOC in the data set were included in the final themes.

Context is a key concept in discourse analysis [45] [46] [48]. To understand the role of context in the samples meaning of PSOC we chose to use Gee's "Framing problem tool". This tool can be used to analyze meaning in context by continually asking and analyzing how contextual aspects affect the meaning of peoples' utterances. Any aspect of context can affect the meaning of an utterance and the researcher uses his/her knowledge of the context to see if aspects of the context are relevant [49]. This tool was applied in the analysis of the core themes in the informants' meaning of PSOC and community (presented below) by asking how any of the related utterances from the sample reflected the Indian context. This way of thinking gave a more context-sensitive understanding by connecting the samples meaning with the larger meaning-systems in their cultural context.

\section{Findings}

The analytical approaches formed several themes important to the urban Indian older adult samples meaning of PSOC. The themes were about helping and sharing with others, giving back to the community, community development, respecting and adapting to other members differences and own safety. The typi- 
cal referent communities mentioned were the family, the neighborhood, the city and India as a nation.

The themes reflected the dimension included in McMillan and Chavis' operationalization; Membership was a central part of the theme "sense of belonging and attachment";

M70: "I think that I am part of the community... I belong to a small group, as well as the larger group... very small group here in Sion [area in Mumbai], as well as the nation, our nation of nearly one billion people".

Furthermore, the themes "Adaptation and acceptance" and "Reciprocity" largely resembled Mutual influence;

F67: Yes [A value I relate to sense of community is]...first one is accepting each other the way they are, without trying to change everybody, you know... and have the respect for whatever their beliefs are, even if I don't agree...

M60: "It [sense of community] is all give and take, it should be that, and it is there. It is there, at least in a place like Mumbai, so many people do that".

Integration and fulfillment of needs was identified in the themes "Respect", "Community expectations" and "Safety and welfare structures";

F61: "For me, the sense of belonging, when you feel that in a community, the values which you will have...should be...respect for elders..."

M70: "You feel bound, attached to...satisfactory. I know my country is fine".

M69: "I want to be in good relation with them [the residential community], and there is also a welfare association to care for the needs...to care for the welfare of the community".

Finally, a shared emotional connection was a central part of the theme "Shared elements" identified in the samples conceptualization:

F67: “... we [from Mumbai] are none of us in a place of origin. We do have a certain culture...but we are very adaptable to the other cultures of my neighbors... Here people have... that sense of acceptance, and that is something very special about this Mumbai..."

There were, however, two additional themes "Helping and caring of others" and "Community heterogeneity" that did not easily fit within the dimensions. As the most salient and as core aspects of the samples meaning of PSOC and community, they will be given special attention.

\subsection{Helping and Caring for Others}

It is almost expected that people speak about help and care when asked about their meaning of PSOC. In our material it was the most evident theme and it operated as a "taken for granted" part of the informants meaning. Words and expressions like "benefit", "work" and "doing something" were typically used. 
For several informants it was part of the very meaning of PSOC:

M65: "Sense of community is the caring of others."

M81: “...sense of community there first of all needs to be an objective. And the objective should be common for all. And most of the objectives should be positive, that is in a helping type".

However, while Western conceptualizations of PSOC typically describe help and care between somewhat equal individuals within a community (e.g. at work) the informants described it as something they provided for less fortunate individuals:

F82: “... our senior citizens used to go there and all the patients used to come, those patients where illiterate, they don't know where to go, so we used to help them...volunteering."

F61: "... we go to the slums... and help with education of the uneducated people..."

Further on it was explained that helping and caring was a way to "give back" to the community:

F82: “... from the community we came up to this level, so we must give it back to the community. That is what I feel is sense of community means."

In this type of community service, some demographical variables seemed to matter. First of all educational background; older adults who identified themselves as "highly educated" (four of the informants) expected themselves and other educated people to make an effort in the community:

M65: "All the educated should have come together and they should try to impart whatever they know... The behavior should be good. Social behavior like helping each other, so because helping others is not an obligation, it is a duty."

Secondly, (widowed) older adults who lived alone seemed to find an especially important purpose and well-being in giving help to the larger community:

M81: "I need them [the family] ... but I don't want... this is better. I am not God himself, but he has given me some power to do something, impact something. So, let me impact."

F61: "If you are in a community you feel 'I am more safe than being outside the community', then you will feel alone.... A sense of safety, a sense of belonging, and sense of wellbeing, mentally and physically. That I am in a good company, and I can also contribute..."

There are several elements within the context, which can help us to understand this theme in a context-sensitive way. First, concept "seva"; "service to others" [50], often understood as a selfless act of worship for a Guru or a social cause [51] [52]. Just as the community efforts the informants described, seva is frequently practiced by volunteering in NGOs [53]. Secondly, according to 
Hinduism and the caste system there are duties which Hindu individuals, as our informants were, are expected to perform are prescribed by caste [31]. The older adult informant who identified as 'highly educated' most likely belong to the highest caste of "Brahmin". In urban areas of India, such as Mumbai, religious practice (including social duties) has been demonstrated as of greater importance for "Brahmins" compared to lower casts [54]. Finally, Hindu philosophy prescribes older adult individuals to withdraw from the material world and the social bonds, such as the family and community life [31] [32] [33]. Then, the finding of community investment as an important and salient part of the "educated" older adults meaning (particularly for those who living alone), seem to be consistent with prior findings that the main motivation for doing seva in old age is a sense of belonging [51], but actually contradicts central age related traditional expectations within their context.

\subsection{Community Heterogeneity}

Established definitions of PSOC are founded upon a membership-similarity understanding of community. In order for PSOC to grow community members need to be alike. The sample from Mumbai, however, shared an understanding of community as consisting of members who were dissimilar. Typically, words like "different", "cosmopolitan" and "mix" were used. Differences in regional religious affiliation, age, interest, professional background and group-identities were described as important in a community:

M67: "I believe that those who stay together, maybe of different regions, maybe of different religions.... But... they should continue to stay together peacefully... that is what I feel a community means."

F61: "A community... is people... not only of the same age, different age groups. Different groups of people having different professions, different interests, but they are staying in the same area."

M65: "Community means that it is a group of people belonging to different race, different caste...but all are living happy. There is no distinction as such."

To adapt to and accept community members' differences was something the informants identified with as "Mumbaikars":

F67: “... we [from Mumbai] are none of us in a place of origin. We do have a certain culture, a basic culture at home, but we are very adaptable to the other cultures of my neighbours... Here people have... that sense of acceptance, and that is something very special about this Mumbai...”

To understand the informant meaning of community in a context-sensitive way we have to look Mumbai as a context. Mumbai can be described as a "MiniIndia" where multiple diverse Indian cultures co-exist. The city is also the most exposed context to Western meaning-systems within the nation [38]. As such the citizens, especially those who have resided there for a long time (as many older adults are likely to) are used to a great heterogeneity of meaning systems. 
In addition it is likely that this form of heterogeneity attracts residents preferring it, and that those who do not favour it have to adapt to it in order be accepted, strengthening diversity as part of the culture further.

\section{Discussion}

\subsection{Psychological Sense of Responsibility}

As presented, personally investing in the well-being of the larger city community was a very important part of the Indian older adults meaning system of PSOC. This form of social responsibility has been acknowledged as a central part of PSOC, particularly, in the element "personal investment" included in the "Membership" dimension [55] [56] [57] [58] [59]. In Nowell and Boyd's recent corollary conceptualization of PSOC [58] the concept is understood as "sense of community responsibility" "... the feeling of personal responsibility for the individual and collective well-being of a community of people, not directly rooted in expectations of personal gain" [59]. The way our sample described PSOC-as helping and caring for others in a way benefiting the larger community-largely resemble PSOC-R by definition. Moreover it mirrors values of collectivism, selflessness and community investment embedded in the Indian cultural context [50] [51] [60]. Then, the informant's meaning exemplify that PSOC-R can be a context-sensitive concept, reflecting key aspects of culture. Furthermore, as our findings suggest, with changes in the family structure (constructing old age outside the family as the norm) and the traditional culture (increasing individualism), this form of responsibility may be especially important for urban older adults PSOC today, despite traditional prescriptions of old age as a withdrawn from social bonds.

\subsection{PSOC and Diversity}

One of the primary values of community psychology has been to build positive communities and at the same time recognize the centrality of diversity. In the field today there is a ongoing discussion about this community-diversity dialectic; One side using agent-based simulation models to explore the dialectic argue that the contextual conditions that foster respect for diversity run in opposition to the ones that foster PSOC [61] [62] [63]. On the other side Brodsky [64] and Hill [65] state that there is no inherent dialectical relationship or conflict inherent to the concepts. Our informants' discourse of community was founded upon diversity as a positive and required aspect, enabling inclusion, acceptance and co-existence of the many meaning systems within the urban context. As such the older adults concept provides an example from the "real world" illustrating community and diversity as interrelated and highly contextual concepts [64], which should be understood from within peoples multiple identities, communities and meaning systems.

\section{Limitations and Reflections on the Study}

Knowledge obtained from the use of discourse analysis is often questioned in 
terms of the falsification that may result from assuming a dialectic relation between the context and discourse practice [49]; reading meaning into text rather than out of text [66]. Interpreting findings in terms of frames of reference or theory is rather common in research, and in qualitative research too. Furthermore, as the thematic analysis was undertaken first, the discourse analysis was based on thorough findings sensitive to the informants' conceptualization of PSOC. The benefit of combining thematic and discourse analysis was that it created an opportunity to expand the in-depth and context-sensitive exploration of meaning. In addition it offered the chance to keep a holistic perspective on the text despite the deconstruction of it, which the thematic analysis requires. However, the informants were not interviewed in their own language and although Indian languages contain several English words and the sample knew English well, doing the interviews in English most likely prevented an ample contextsensitive understanding of the informants' discourses.

Qualitative analysis of culture and social contexts calls for the researchers themselves to be scrutinized. The bi-cultural perspective (Norwegian-Indian) of the researcher in the current study is believed to have affected the interpretations. The "outside" perspective enabled a possibility to point out biases and taken for granted notions assumed to be natural, which actually were cultural. The "inside" perspective had the benefit of understanding the Indian culture and to be perceived as of Indian origin by the informants. However, it is also likely that this perspective have introduced some biases as well; Cultural aspects of the samples meaning may have been understood as cultural, because they stood out as very different from a Norwegian culture. The perspective is also likely to have made the researcher blind to some of the taken for granted elements that the researcher shared with the informants.

Another limitation concerns the fact that the informants were not asked about their caste. Although most Indian people will know people's caste from the moment an individual says his/her surname, this was not something the researcher was able to do. Asking about caste was avoided because the informant could perceive it as intrusive. Future research should include questions about caste in a sensitive way (e.g. "Would you say that caste has any influence on your sense of community?"), as it is vital to understand social and cultural phenomena in the Indian context.

\section{Conclusion}

As illustrated, the Indian older adult city samples' meaning of PSOC and community reflected the dimensions included in McMillan and Chavis' (1986) conceptualization. However, two core themes were detected which illustrate PSOC$\mathrm{R}$ and diversity as culture-bound and context-specific concepts inherent in their meanings. As previous studies [11] [67], this study illustrates that later-life PSOC is largely influenced by the context and that many older adults are highly adjustable to large-scale changes potentially devastating to their PSOC. And once again, premises to older adults PSOC seem to be interrelated to culture [11] 
in this case both at a national as well as city level. Communities outside the family and acceptance of heterogeneity seem to be ever so important for urban older adults PSOC and well-being in urban India today. It is important that the interrelation between older adults meaning systems of PSOC and culture is further investigated in additional contexts to generate a stronger and context-sensitive understanding of PSOC in old age across the fast-changing population ageing world.

\section{Acknowledgements}

We would like to thank Tata Institute of Social Sciences, Professor Siva Raju and the field workers Arundhati Sanyal and Laxmi Rao for assisting in the data collection. We would also like to thank the older adult informants for participating in our study.

\section{References}

[1] Davidson, W.B. and Cotter, P.R. (1991) The Relationship between Sense of Community and Subjective Well-Being: A First Look. Journal of Community Psychology, 19, 246-253.

https://doi.org/10.1002/1520-6629(199107)19:3<246::AID-JCOP2290190308>3.0.C $\underline{\mathrm{O} ; 2-\mathrm{L}}$

[2] Prezza, M., Amici, M., Roberti, T. and Tedeschi, G. (2001) Sense of Community Referred to the Whole Town: Its Relations with Neighboring, Loneliness, Life Satisfaction, and Area of Residence. Journal of Community Psychology, 29, 29-52. https://doi.org/10.1002/1520-6629(200101)29:1<29::AID-JCOP3>3.0.CO;2-C

[3] Prezza, M. and Costantini, S. (1998) Sense of Community and Life Satisfaction: Investigation in Three Different Territorial Contexts. Journal of Community \& Applied Social Psychology, 8, 181-194.

https://doi.org/10.1002/(SICI)1099-1298(199805/06)8:3<181::AID-CASP436>3.0.C $\underline{\mathrm{O} ; 2-4}$

[4] Farrell, S.J., Aubry, T. and Coulombe, D. (2004) Neighborhoods and Neighbors: Do They Contribute to Personal Well-Being? Journal of Community Psychology, 32, 9-25. https://doi.org/10.1002/jcop.10082

[5] Lynch, K.M. (2012) Positive Aging: The Relationships between Satisfaction with Life and Sense of Community with Place of Residence. PhD, National-Louis University, Chicago.

[6] Fisher, A.T., Sonn, C.C. and Bishop, B.J. (2002) Psychological Sense of Community: Research, Applications, and Implications. Kluwer Academic, New York. https://doi.org/10.1007/978-1-4615-0719-2

[7] Nelson, G. and Prilleltensky, I. (2005) Community Psychology: In Pursuit of Liberation and Well-Being. Palgrave Macmillan, New York.

[8] Dalton, J.H., Elias, M.J. and Wandersman, A. (2007) Community Psychology: Linking Individuals and Communities. Thomson Wadsworth, Belmont.

[9] Bess, K.D., Fisher, A.T., Sonn, C.C. and Bishop, B.J. (2002) Psychological Sense of Community: Theory, Research, and Application. Psychological Sense of Community, Kluwer Academic, New York, 3-22. https://doi.org/10.1007/978-1-4615-0719-2_1

[10] Sarason, S.B. (1974) The Psychological Sense of Community: Prospects for a Com- 
munity Psychology. Jossey-Bass Limited, London.

[11] Bahl, N.K.H., Nafstad, H.E., Blakar, R.M. and Geirdal, A.Ø. (2017) Responsibility for Psychological Sense of Community and Well-Being in Old Age: A Qualitative Study of Urban Older Adults in Norway. Manuscript accepted for publication in Open Journal of Social Sciences.

[12] McMillan, D.W. and Chavis, M. (1986) Sense of Community: A Definition and Theory. Journal of Community Psychology, 14, 6-23. https://doi.org/10.1002/1520-6629(198601)14:1<6::aid-jcop2290140103>3.0.co;2-i

[13] Brodsky, A.E. (2009) Multiple Psychological Senses of Community in Afghan Context: Exploring Commitment and Sacrifice in an Underground Resistance Community. American Journal of Community Psychology, 44, 176-187. https://doi.org/10.1007/s10464-009-9274-4

[14] Cheng, S.-T. and Heller, K. (2009) Global Aging: Challenges for Community Psychology. American Journal of Community Psychology, 44, 161-173. https://doi.org/10.1007/s10464-009-9244-x

[15] Siva Raju, S. (2002) Meeting the Needs of the Poor and Excluded in India. Situation and Voices, the Older Poor and Excluded in South Africa and India, UNFPA. Population and Development Strategies, 2, 93-110.

[16] Sonn, C.C., Bishop, B.J. and Drew, N.M. (1999) Sense of Community: Issues and Considerations from a Cross-Cultural Perspective. Community, Work \& Family, 2, 205-218. https://doi.org/10.1080/13668809908413941

[17] Hill, J.L. (1996) Psychological Sense of Community: Suggestions for Future Research. Journal of Community Psychology, 24, 431-438.

https://doi.org/10.1002/(SICI)1520-6629(199610)24:4<431::AID-JCOP10>3.0.CO;2$\underline{\mathrm{T}}$

[18] Mannarini, T. and Fedi, A. (2009) Multiple Senses of Community: The Experience and Meaning of Community. Journal of Community Psychology, 37, 211-227. https://doi.org/10.1002/jcop.20289

[19] Talò, C., Mannarini, T. and Rochira, A. (2014) Sense of Community and Community Participation: A Meta-Analytic Review. Social Indicators Research, 117, 1-28. https://doi.org/10.1007/s11205-013-0347-2

[20] Mak, W.W., Cheung, R.Y. and Law, L.S. (2009) Sense of Community in Hong Kong: Relations with Community-Level Characteristics and Residents' Well-Being. American Journal of Community Psychology, 44, 80-92. https://doi.org/10.1007/s10464-009-9242-z

[21] Waid, L.D. and Frazier, L.D. (2003) Cultural Differences in Possible Selves during Later Life. Journal of Aging Studies, 17, 251-268.

[22] Chiu, C.-Y. and Hong, Y.-Y. (2013) Social Psychology of Culture. Psychology Press, New York.

[23] Triandis, H.C. (1995) Individualism \& Collectivism. Westview Press, Boulder.

[24] Triandis, H.C. (1996) The Psychological Measurement of Cultural Syndromes. American Psychologist, 51, 407-415. https://doi.org/10.1037/0003-066X.51.4.407

[25] Verma, J. and Triandis, H.C. (1999) The Measurement of Collectivism in India. International Congress of the International Association for Cross-Cultural Psychology, Western Washington U, Bellingham, WA, 14 August 1998, Swets \& Zeitlinger Publishers.

[26] Shah, G. (2009) The Impact of Economic Globalization on Work and Family Collectivism in India. Journal of Indian Business Research, 1, 95-118.

https://doi.org/10.1108/17554190911005318 
[27] Sinha, J.B. and Kumar, R. (2005) Methodology for Understanding Indian Culture. The Copenhagen Journal of Asian Studies, 19, 89-104.

[28] Sinha, J.B.P., Sinha, T., Verma, J. and Sinha, R. (2001) Collectivism Coexisting with Individualism: An Indian Scenario. Asian Journal of Social Psychology, 4, 133-145. https://doi.org/10.1111/j.1467-839X.2001.00081.x

[29] Sokolovsky, J. (2009) The Cultural Context of Aging: Worldwide Perspectives. Praeger Publishers, Westport.

[30] De Silva, I. (2003) Demographic and Social Trends Affecting Families in the South and Central Asian Region. Major Trends Affecting Families: A Background Document, 45.

[31] Bhawuk, D.P.S. (2008) Globalization and Indigenous Cultures: Homogenization or Differentiation? International Journal of Intercultural Relations, 32, 305-317.

[32] Rowles, G.D. and Chaudhury, H. (2005) Home and Identity in Late Life: International Perspectives. Springer Publishing Company, New York.

[33] Bhawuk, D.S. (2011) Indian Concept of Self. In: Spirituality and Indian Psychology, Springer, New York, 65-91. https://doi.org/10.1007/978-1-4419-8110-3_4

[34] Dirks, N.B. (2001) Castes of Mind: Colonialism and the Making of Modern India. Princeton University Press, Princeton, New Jersey.

[35] Bros, C. (2014) The Burden of Caste on Social Identity in India. The Journal of Development Studies, 50, 1411-1429. https://doi.org/10.1080/00220388.2014.940908

[36] Kumari Bhat, A. and Dhruvarajan, R. (2001) Ageing in India: Drifting Intergenerational Relations, Challenges and Options. Ageing and Society, 21, 621-640.

https://doi.org/10.1017/S0144686X0100842X

[37] United Nations (2015) World Urbanization Prospects: The 2014 Revision. Department of Economic and Social Affairs (DESA), Population Division, Population Estimates and Projections Section, New York.

[38] Patel, S. (2004) Bombay/Mumbai: Globalization, Inequalities, and Politics. In: Gugler, J., Ed., World Cities beyond the West: Globalization, Development and Inequality, Cambridge University Press, Cambridge, 328. https://doi.org/10.1017/cbo9780511550799.013

[39] Cicognani, E., Klimstra, T. and Goossens, L. (2014) Sense of Community, Identity Statuses, and Loneliness in Adolescence: A Cross-National Study on Italian and Belgian Youth. Journal of Community Psychology, 42, 414-432. https://doi.org/10.1002/jcop.21618

[40] Carlson, N., Martin, G. and Buskist, W. (2007) Psychology. Pearson Education Limited, Pearson Education, Harlow, Essex.

[41] Braun, V. and Clarke, V. (2006) Using Thematic Analysis in Psychology. Qualitative Research in Psychology, 3, 77-101. https://doi.org/10.1191/1478088706qp063oa

[42] Clarke, V., Braun, V. and Hayfield, N. (2015) Thematic Analysis. In: Smith, J.A., Ed., Qualitative Psychology: A Practical Guide to Research Methods, SAGE Publications, London, 222-248.

[43] Howitt, D. (2010). Introduction to Qualitative Methods in Psychology. Prentice Hall, Harlow.

[44] Billig, M. (2001) Discursive, Rhetorical and Ideological Messages. In: Magarett Wetherell, S.T. and Yates, S.J., Eds., Discourse Theory and Practice: A Reader, SAGE Publications, New Delhi, 210-221.

[45] Gee, J.P. (2014) An Introduction to Discourse Analysis: Theory and Method. Routledge, Oxon. 
[46] Fairclough, N. (2010) Critical Discourse Analysis: The Critical Study of Language. Prentice Hall, Routledge, New York.

[47] Nafstad, H.E. and Blakar, R.M. (2012) Ideology and Social Psychology. Social and Personality Psychology Compass, 6, 282-294. https://doi.org/10.1111/j.1751-9004.2012.00428.x

[48] Wodak, R. and Meyer, M. (2009) Methods for Critical Discourse Analysis. SAGE Publications, Thousand Oaks, CA.

[49] Gee, J.P. (2014) How to Do Discourse Analysis. 2nd Edition: A Toolkit. Routledge, Oxon.

[50] Jacobsen, K.A. (2014) Hinduism and Globalization. In: Bryan S. Turner, O.S., Eds., Routledge Handbook of Religions in Asia, Routledge, Oxon, 359.

[51] Pandya, S. (2014) Seva as a Form of Faith-Based Social Work in India. Global Journal of Human-Social Science Research, 14.

[52] Srinivas, S. (2008) In the Presence of Sai Baba: Body, City, and Memory in a Global Religious Movement. Brill, Leiden. https://doi.org/10.1163/ej.9789004165434.i-403

[53] Bornstein, E. (2012) Disquieting Gifts: Humanitarianism in New Delhi. Stanford University Press, Stanford.

[54] Stroope, S. (2012) Caste, Class, and Urbanization: The Shaping of Religious Community in Contemporary India. Social Indicators Research, 105, 499-518. https://doi.org/10.1007/s11205-011-9784-y

[55] Boyd, N.M. and Nowell, B. (2013) Psychological Sense of Community: A New Construct for the Field of Management. Journal of Management Inquiry, 23, 107-122.

[56] McMillan, D.W. (2011) Sense of Community, a Theory Not a Value: A Response to Nowell and Boyd. Journal of Community Psychology, 39, 507-519. https://doi.org/10.1002/jcop.20439

[57] Nowell, B. and Boyd, N. (2011) Sense of Community as Construct and Theory: Authors' Response to McMillan. Journal of Community Psychology, 39, 889-893. https://doi.org/10.1002/jcop.20504

[58] Nowell, B. and Boyd, N. (2010) Viewing Community as Responsibility as Well as Resource: Deconstructing the Theoretical Roots of Psychological Sense of Community. Journal of Community Psychology, 38, 828-841.

https://doi.org/10.1002/jcop.20398

[59] Nowell, B. and Boyd, N.M. (2014) Sense of Community Responsibility in Community Collaboratives: Advancing a Theory of Community as Resource and Responsibility. American Journal of Community Psychology, 54, 229-242. https://doi.org/10.1007/s10464-014-9667-x

[60] Triandis, H.C. and Gelfand, M.J. (1998) Converging Measurement of Horizontal and Vertical Individualism and Collectivism. Journal of Personality and Social Psychology, 74, 118-128. https://doi.org/10.1037/0022-3514.74.1.118

[61] Neal, Z.P. and Neal, J.W. (2014) The (In)Compatibility of Diversity and Sense of Community. American Journal of Community Psychology, 53, 1-12. https://doi.org/10.1007/s10464-013-9608-0

[62] Neal, Z.P. (2017) Taking Stock of the Diversity and Sense of Community Debate. American Journal of Community Psychology, 59, 255-260. https://doi.org/10.1002/ajcp.12132

[63] Stivala, A., Robins, G., Kashima, Y. and Kirley, M. (2016) Diversity and Community Can Coexist. American Journal of Community Psychology, 57, 243-254. https://doi.org/10.1002/ajcp.12021 
[64] Brodsky, A.E. (2017) Bridging the Dialectic: Diversity, Psychological Sense of Community, and Inclusion. American Journal of Community Psychology, 59, 269271. https://doi.org/10.1002/ajcp.12135

[65] Hill, J.L. (2017) Where Is the Dialectic in the Community-Diversity Dialectic? American Journal of Community Psychology, 59, 276-279.

[66] Haig, E. (2004) Some Observations on the Critique of Critical Discourse Analysis. Studies in Language and Culture, 25, 129-149.

[67] Li, W.W., Hodgetts, D. and Sonn, C. (2014) Multiple Senses of Community among Older Chinese Migrants to New Zealand. Journal of Community \& Applied Social Psychology, 24, 26-36. https://doi.org/10.1002/casp.2174

Submit or recommend next manuscript to SCIRP and we will provide best service for you:

Accepting pre-submission inquiries through Email, Facebook, LinkedIn, Twitter, etc. A wide selection of journals (inclusive of 9 subjects, more than 200 journals)

Providing 24-hour high-quality service

User-friendly online submission system

Fair and swift peer-review system

Efficient typesetting and proofreading procedure

Display of the result of downloads and visits, as well as the number of cited articles Maximum dissemination of your research work

Submit your manuscript at: http://papersubmission.scirp.org/

Or contact jss@scirp.org 